\title{
Das séries aos ciclos de estudos: o desafio da (des)continuidade.
}

- Doralice Aparecida Paranzini Gorni

- Alini Falcão dos Santos **

\section{Resumo}

A partir da década de 1980 iniciou-se a reorganização das tradicionais séries do ensino fundamental brasileiro em ciclos, sustentada no princípio da ampliação do tempo de aprendizagem do aluno e na idéia de continuidade. 0 trabalho objetivou investigar as práticas avaliativas em uma escola pública organizada em ciclos, bem como, as condições necessárias para a concretização da avaliação formativa no seu cotidiano. Consistiu em uma pesquisa qualitativa que propôs a adequação da avaliação do aluno, sendo realizada de 2004 a 2006. Foi desenvolvida em quatro etapas: realização de grupo de estudos junto às docentes e equipe técnico-pedagógica da escola; assessoramento às docentes para elaboração de planejamento anual e bimestral; elaboração de fichas para acompanhamento do desempenho dos alunos; assessoramento às docentes no preenchimento das fichas de suas respectivas turmas e a realização de reuniões mensais para avaliação e encaminhamento das dificuldades encontradas, na construção de uma prática avaliativa continuada e reflexiva. Obteve-se resultado positivo junto a 50\% das docentes. A alta rotatividade destes foi o maior problema enfrentado. Destaca-se a necessidade de elaboração de políticas que a combatam e garantam aos professores condições para se envolverem em projetos voltados à melhoria do trabalho pedagógico e ao enfrentamento das dificuldades existentes no cotidiano escolar.

Palavras-chave: Políticas educacionais. Ensino Fundamental. Ciclo de estudos. Avaliação formativa.

\section{From grades to study cycles: the challenge of the (dis)continuity Abstract}

During the 1980's, the reorganization of the Brazilian traditional grades of elementary school into cycles began, based on the principle of enlarging the

"Doutora em Educação. Professora Associada do Departamento de Psicologia Social e Institucional da Universidade Estadual de Londrina/UEL. Docente do Programa de Mestrado em Educação da UEL. E-mail: doragorni@uel.br

“ Bolsista do PROIC/CNPq. E-mail: alini_fs@yahoo.com.br 
students' learning period and on the idea of continuity. This study aimed to investigate the evaluation practices in a public school organized in cycles, as well as the necessary conditions to implement the formative assessment in their daily lives. A qualitative study held from 2004 to 2006 proposed the adequacy of the students' evaluation. The research was developed in four stages: a study group with the teachers and the technical-pedagogical body was carried out; assistance to teachers in the preparation of their annual and bimonthly schedules; development of cards to monitor the students' performance; help teachers fill out their classes cards and monthly meetings to evaluate and route the difficulties encountered in the construction of a continuous and reflexive assessment practice. Positive results were obtained with 50\% of the teachers. The high turnover of teachers was the major problem, which highlights the necessity of formulating policies to combat it and also to ensure teachers conditions to take part in projects which aim to improve the pedagogical work and to cope with the difficulties in the daily school life.

Keywords: Educational policies. Elementary school. Cycles system. Formative assessment

\section{De los grados a los ciclos de estudios: el desafío de la (des)continuidad Resumen}

Se ha empezado, en el sistema educacional brasileño, a contar de la década de 1980, la reestructuración de los grados tradicionales de la enseñanza básica en ciclos, apoyada en el fundamento de la ampliación del tempo de aprendizaje del alumno, con la idea de continuidad implícita en ella. El estudio presente ha objetivado investigar las prácticas evaluativas en una escuela pública cuyo currículum es organizado en ciclos de estudios, así como las condiciones necesarias a la concretización de la evaluación formativa en su cotidiano. Este trabajo ha sido basado en una encuesta cualitativa que propuso la adecuación de la evaluación del alumno a la de la escuela en ciclos de estudios e fue realizado de 2004 a 2006 en cuatro etapas: grupo de estudios realizado con el profesorado del $1^{\circ}$ al $4^{\circ}$ grados juntamente con el cuadro técnico-pedagógico de dicha escuela; asesoramiento individual al profesorado para trabajarse en la planificación anual y bimestral; elaboración de fichas para el acompañamiento del desempeño de los alumnos; asesoramiento al profesorado cuanto al relleno de las fichas de sus respectivas clases, además de la realización de reuniones mensuales para evaluarse y encaminar las dificultades encontradas, visando la construcción de un instrumento que posibilitara la elaboración de un método de evaluación continuado y reflexivo, integrado a la práctica pedagógica. Se obtuvo un resultado positivo junto a 50\% del profesorado. Es necesario resaltar la necesidad de hacer el profesorado efectivo en las escuelas por mediante la elaboración de politicas que combatan el elevado 
grado rotativo de profesores y que les garanticen condiciones para que ellos se envuelvan en proyectos que contribuyan para la mejoría de la calidad de la práctica pedagógica y para enfrentar las dificultades existentes en el cotidiano de la escuela. Palabras clave: Politicas educativas. Enseñanza fundamental. Ciclos de estudios. Evaluación formativa.

\section{Introdução}

Ao longo do seu desenvolvimento, a educação brasileira tem sido marcada pela descontinuidade das políticas educacionais, bem como dos programas e projetos implementados pelos diferentes governantes. Tal fato pode ser atribuído à inexistência de um projeto educacional construído no bojo da sociedade brasileira e, em decorrência, à implantação de programas de governo com duração coincidente à de seus mandatos, ou seja, interrompidas a cada alternância no poder.

Neste cenário, superar a descontinuidade das políticas educacionais implementadas em nosso país, ao longo de sua história, em favor da continuidade desejada, tem sido o maior desafio com que se tem deparado o sistema educacional nas últimas décadas. Sob este ponto de vista, a proposição da avaliação formativa e qualitativa em substituição à avaliação quantitativa e classificatória, a reorganização das tradicionais séries em ciclos de estudos e a introdução de pareceres descritivos acerca do rendimento do aluno, em substituição ao tradicional sistema de notas, são ações significativas que foram introduzidas nos meados da década de 1980, no sistema educacional brasileiro e, em especial, no estado do Paraná, logo após o início do processo de abertura democrática do país, que se mantiveram na reforma educacional dos anos 90, conforme análise realizada por Gorni (1999).

Tais proposições provocaram a necessidade de revisão e alteração das posturas e práticas vigentes no contexto escolar, uma vez que respondiam à necessidade de realização de ações que contribuíssem para o desenvolvimento de um ensino de boa qualidade, como enfatizaram Gomes (2005); Duran, Alves e Palma Filho (2005). No intuito de verificar em que medida estavam ocorrendo estas modificações, Gorni e outros (2003) realizaram uma investigação que permitiu constatar, no que se refere à avaliação do desempenho dos alunos, a predominância das avaliações formais sobre as informais e de alguns conteúdos e disciplinas em detrimento de outros na elaboração das avaliações formais aplicadas aos alunos da $4^{a}$ série do Ensino Fundamental, em três escolas públicas, localizadas na região central e na periferia de Londrina-PR.

Esta situação denota, segundo as autoras, a manutenção de algumas práticas docentes e avaliativas caracteristicas da escola tradicional, num contexto em que deveriam ter sido substituídas e/ou complementadas por outras que primassem pela avaliação para além do simples domínio de conteúdos por parte do aluno, e que 
permitissem verificar se estava ocorrendo a integração dos conhecimentos veiculados pelas diferentes áreas, bem como sua aplicabilidade a situações reais servindo, desta forma, como subsídio para a elaboração dos pareceres parciais e finais sobre o desempenho individual do aluno ao longo do ano letivo.

A realização da investigação tornou ainda evidente que, apesar da possibilidade de reestruturação das séries em ciclos, cuja lógica sugere o rompimento com o isolamento do trabalho pedagógico da tradicional organização em séries, objetivando introduzir um continuum que permita ao aluno a ampliação do tempo de aprendizagem, o planejamento do trabalho docente continuava sendo um trabalho solitário.

Da mesma forma, a avaliação do rendimento do aluno permanecia, predominantemente, domínio do professor da turma, ou seja, como trabalho de responsabilidade exclusiva do docente de cada "série", durante grande parte do ano letivo, embora semestralmente referendado pelo conselho de classes. Esta observação gerou uma preocupação que encontra respaldo na afirmação de Duran, Alves e Palma Filho (2005, p.103), quando afirmam que 'o conceito original de ciclo exige a ruptura com a forma tradicional de avaliar o aproveitamento do aluno e o processo pedagógico".

Com este entendimento, observamos que tal fato dificulta a continuidade do trabaIho na escola em ciclos, uma vez que muitos docentes mudam de escola no final do ano e nem sempre se tem registro ou informação detalhada sobre o desempenho de cada aluno nos anos anteriores, que sendo acessivel aos novos docentes, possam servir como base para o planejamento do trabalho a ser desenvolvido junto aos mesmos.

De maneira complementar, a investigação de Gorni e outros (2003) revelou que embora os professores realizassem diferentes avaliações junto a seus alunos no decorrer do ano letivo, eram as avaliações formais que subsidiavam a elaboração dos pareceres oficiais descritivos sobre o desempenho do aluno, fossem eles parciais ou finais. Desta forma, as avaliações informais, ou seja, as que o professor realizava no dia-a-dia, mediante a utilização de diferentes estratégias, embora fossem utilizadas para o realinhamento do trabalho pedagógico, tinham como maior valor, na opinião das docentes, detectar o "melhor momento" para a aplicação das avaliações formais. Sendo assim, não possuiam valor de documentos oficiais para o sistema. Tal procedimento tinha, por sua vez, o intuito de salvaguardar os professores e a escola de possiveis contestações dos pais e dos alunos acerca da avaliação atribuída a seu rendimento anual.

Este fato evidencia uma contradição: embora o sistema educacional recomende a realização da avaliação processual, ela não tem valor de 'documento comprobatório' no interior do próprio sistema. Isto sugere que, embora a indique, o próprio sistema não tem confiabilidade na forma como a avaliação processual se desenvolve no seu interior. 
Sendo assim, confirma-se que as políticas educacionais não têm, pela sua simples proposição, o poder de garantir a continuidade do processo de ensino e aprendizagem dentro de um mesmo ciclo e nem o alinhamento da prática de avaliação com as proposições vigentes, pois ainda que as bases legais do sistema tenham estabelecido a existência desta continuidade, bem como as orientações para a realização de uma nova forma de avaliação do aluno, condizente com as mesmas, nenhuma ou pouca mudança significativa havia ocorrido no contexto da escola a este respeito.

Disto decorre que, apesar da extensão do tempo para aprender e da indicação da avaliação de processo terem sido introduzidas e posteriormente incorporadas às determinações legais, a partir do início da década de 80 , com o intuito de romper com as práticas e pensamento educacional tradicional, persistem nas escolas alguns conceitos e preconceitos, mitos e ritos, atuando no sentido de manter e preservar a estrutura e organização tradicional do sistema. Infelizmente, esta situação não é inerente a esta ou uma escola, ou a um estado da federação, especificamente (GORNI, 1999).

Neste sentido, observa-se que a ausência das condições reais para a concretização das diretrizes propostas, somada a outros fatores tem, por vezes, mantido no interior das instâncias executivas periféricas do sistema educacional (Núcleos Regionais de Ensino e escolas), uma prática burocratizada voltada mais para o cumprimento das normas e metas estabelecidas nas instâncias centrais do sistema, do que a elaboração do projeto da escola voltado ao atendimento das necessidades da população e comunidade atendida, como estabelece a Lei 9394/96.

Sob este aspecto, podemos afirmar que o estabelecimento de espaços de participação, autonomia e gestão legalmente 'garantidos' às instituições educacionais não têm sido realmente ocupados para introduzir caminhos singulares no contexto de cada escola, posto que, na grande maioria destas, observa-se como destaca Souza (2003), que a autonomia foi dada a quem não sabia o que fazer com ela.

Neste sentido, cabe ainda destacar que embora a lei garanta um 'certo espaço' para que os estados e as instituições educacionais abordem suas questões e necessidades específicas, visando permitir a contemplação da regionalidade e da singularidade que possuem, ao estabelecer, concomitantemente, o que denominou 'parâmetros' para todo o sistema, intencionalmente ou não, deixou pouco espaço para que a escola exercesse sua autonomia e caminhasse na construção de sua própria identidade, na medida em que a maioria das escolas acomoda-se no cumprimento das solicitações e normas estabelecidas, conforme a boa tradição de instância executiva do sistema, deixando de concentrar-se na busca de alternativas e/ou estratégias que poderiam levá-la a tentar sanar suas dificuldades e necessidades. 
Não bastasse este aspecto, há também elementos constitutivos da cultura dos professores que interferem na aceitação e resistência às inovações propostas ou impostas ao sistema, como relata Coelho (2003). Conforme enfatiza a autora, a aceitação das inovações pelos docentes não se dá de forma imediata e está diretamente relacionada à obtenção de resultados positivos, a partir das mesmas, ao longo do tempo. É principalmente sob esta perspectiva que se pode explicar a lentidão com que a organização da escola em ciclos e a introdução da avaliação qualitativa vêm ganhando a adesão dos educadores, após sua implantação em meados da década de 80.

Assim como Coelho (2003), Valente (2002) entrevistou professores focalizando aspectos da reforma do sistema educacional introduzida no estado do Paraná. Os dois trabalhos destacam aspectos relacionados à formação, capacitação, reconhecimento e condições de estrutura e de desenvolvimento do trabalho docente como pontos frágeis da reforma. Sem dúvida, por todas as razões arroladas anteriormente, apesar das propostas desfrutarem de um razoável nivel de aceitação entre os professores, continuam a ser objeto de críticas, reflexões e, principalmente, resistência.

Com relação à existência de coerência entre diferentes aspectos da reforma, cabe destacar que a proposta de organização da escola em ciclos deixa clara a indicação da avaliação formativa e continuada, como sendo a mais adequada ao desenvolvimento e aprimoramento do processo de ensino e aprendizagem. Porém, não deveriam restar dúvidas quanto ao fato de que a escola organizada em ciclos pressupõe, necessariamente, uma avaliação por ciclo. Desta forma, a introdução da elaboração do parecer descritivo do docente acerca do desempenho do aluno, em substituição às notas, deveria ser um elemento a mais e, diga-se de passagem, de extrema relevância para o encaminhamento do trabalho pedagógico desenvolvido junto ao aluno. No entanto, a elaboração de pareceres "padronizados" conforme relata ocorrer Souza (2003), pouco ou nada acrescenta à avaliação e planejamento da ação docente junto a cada aluno, especificamente.

Neste sentido observa-se um descompasso na reforma, na medida em que o aluno estuda em uma escola organizada em ciclos, mas os professores, por vezes, continuam trabalhando em uma escola organizada em séries. Deduz-se pois, que devem ser buscadas condições efetivas de continuidade do processo de ensino e aprendizagem que passam, com certeza, pela organização do trabalho docente e do acompanhamento do rendimento do aluno ao longo do ciclo e não apenas no decorrer de cada ano letivo.

Assim, a avaliação feita por cada professor em cada ano letivo, só tem sentido na escola em ciclo, quando compõe o quadro de acompanhamento do desempenho de cada aluno ao longo do ciclo de estudos em que este se encontra. Desta forma, cada professor individualmente e todos os professores em conjunto são co-responsáveis pelo processo de aprendizagem vivenciado por cada aluno na escola. Ou seja, todos os professores são, individual e coletivamente, responsáveis pela aprendizagem ou não de cada aluno. 
Sob este enfoque, a elaboração de pareceres descritivos semestrais deveria ser complementada por registros, exemplares de atividades realizadas pelo aluno e relatos do docente contendo a descrição do desempenho deste, que podem demonstrar sua 'competência' cognitiva, afetiva e social. 0 conjunto de tais dados possibilitaria a construção de um portfólio do aluno ao longo do ciclo de estudos, permitindo garantir a continuidade do processo de aprendizagem ao longo do mesmo, em substituição às provas pontuais, que na sua grande maioria, deixam evidente uma tendência a construir padrões ou modelos que muitas vezes, devido às precárias condições de tempo e condições para sua realização, não mais permitem que a classificação e o enquadramento dos alunos em um padrão ou categoria, que acaba desconsiderando as particularidades do seu desempenho.

Portanto, é importante romper com este modelo de avaliação para avançar na melhoria de qualidade do sistema educacional. E sob este prisma, é que a avaliação processual e contínua do aluno deve tornar-se o eixo norteador do trabalho dos docentes ao longo dos ciclos de estudos. Nesta perspectiva, a avaliação e o trabalho pedagógico são altamente relacionados e interdependentes, não podendo introduzir alterações em um sem que se provoquem alterações no outro, como enfatiza Perrenoud (1999).

Visto desta forma, torna-se relevante a necessidade de conscientização do professor acerca da importância do conhecimento de cada aluno, na sua singularidade, atentando para suas características de aprendizagem, bem como, suas facilidades e dificuldades ao longo do processo educacional, visando, mediante o respeito ao ritmo e às características dos mesmos, a organização das estratégias de ensino que Ihes permitam superar, gradualmente, as dificuldades encontradas no percurso.

É com base neste entendimento que devem ser estabelecidas as metas dos diferentes ciclos na Proposta Pedagógica das escolas e, neste sentido, o trabalho relatado objetivou a investigação do modo que vem sendo desenvolvido o processo de avaliação dos alunos; assim como assessorar os professores na construção de um instrumento de acompanhamento do desempenho dos mesmos para ser utilizado ao longo do ciclo de estudos que compreende as séries iniciais do Ensino Fundamental em uma escola pública estadual.

\section{Sobre a avaliação do e no processo}

As práticas avaliativas que vêm sendo realizadas nas instituições de ensino mostramse, muitas vezes, incompatíveis com a proposta de educação democrática, já que se caracterizam como classificatórias e eliminatórias. Hoffmann (2001) afirma que essas práticas tradicionais de avaliação baseiam-se entre o pretendido e o alcançado, sendo os pontos de partida e os pontos de chegada, os parâmetros para avaliação da aprendizagem dos alunos. A principal preocupação dos avaliadores está em apontar os resultados obtidos, com base em critérios fixados e delimitados a priori pelo educador. 
Por esta lógica, a aprovação e a reprovação são embasadas nos resultados destas avaliações classificatórias. Porém, na medida em que classifica os alunos entre capazes e incapazes, o próprio sistema educacional acaba por promover a exclusão social e admitir sua incapacidade de ensinar a todos indistintamente. Esta é a principal razão por que se torna necessária a reflexão sobre as práticas avaliativas. Ela parte do princípio de que a avaliação deve ser marcada por um agir consciente e reflexivo, que deve estar a serviço da melhoria da qualidade da educação, ao apontar em que ponto do processo os alunos estão e quais caminhos podem ser adotados para prosseguir.

Sob esta ótica, a superação do caráter classificatório das práticas tradicionais de avaliação, segundo a autora, é feita através da retomada do sentido ético destas, do respeito às diferenças, do compromisso com a aprendizagem de todos e da formação para a cidadania. Para tanto, é importante uma reflexão coletiva, envolvendo avaliadores e estudiosos, sobre os princípios que norteiam as práticas avaliativas e os possíveis rumos que a avaliação pode seguir.

Neste sentido, propor mudanças no processo avaliativo, não implica apenas em alterar os procedimentos utilizados, mas também as finalidades dos mesmos. Os resultados obtidos por meio das avaliações devem ser encarados como indícios para a continuidade do processo de aprendizagem, mediante uma ação voltada ao futuro que respeite as possibilidades dos alunos.

Em consonância com esta perspectiva, a avaliação mediadora proposta por Hoffmann (2001) apresenta como principais características estar voltada ao futuro; a melhoria da própria situação avaliada; possibilitar um comprometimento do professor e da escola com o conhecimento e respeito às diferenças; levar em consideração a individualidade dos alunos, sem perder de vista o grupo; e ser marcada por uma ação pedagógica reflexiva.

A proposta de uma prática avaliativa voltada ao futuro implica, necessariamente, em um acompanhamento sério e comprometido de todas as etapas vivenciadas pelos alunos, de forma a possibilitar o ajuste das estratégias pedagógicas, visando auxiliar a evolução da aprendizagem dos mesmos. Ao se basearem no sucesso futuro, as tarefas avaliativas passam a ser encaradas apenas como pontos de passagem, os quais possibilitam proceder com ações educativas que otimizem os percursos de cada aluno, caracterizando uma ação voltada ao educando e não mais ao simples cumprimento de currículos.

Hoffmann (op.cit.) destaca também que a aprendizagem do aluno ocorre conforme as descobertas, as dúvidas e as retomadas forem acontecendo, não seguindo um trajeto linear. Da mesma forma, cada aluno possui dificuldades e facilidades singulares, o que implica na necessidade de tempos diferentes para a construção de 
determinados raciocínios. Neste caso, a avaliação mediadora, é um instrumento que permite ao educador respeitar as diferenças no ritmo de cada aluno, na medida em que defende que cada um siga sua trajetória, apesar de todas convergirem para uma mesma direção: a evolução do conhecimento.

Em decorrência, o respeito aos diferentes ritmos dos alunos torna possivel a utilização desta prática em regimes não-seriados, visto estes terem como proposta o acompanhamento longitudinal dos mesmos. Por esta razão, podemos afirmar que a avaliação contínua exige uma reformulação do conceito de 'tempo' em educação, já que tem como foco o caminho percorrido pelo aluno e não apenas os pontos de partida e de chegada do mesmo. Dizendo de outra forma, é no dia-a-dia da sala de aula que o aluno apresenta sinais de que avançou em certos pontos de sua trajetória e a avaliação mediadora deve ser planejada e sistematizada de forma a permitir que o professor consiga captar estes sinais.

Em sua essência, o ato de avaliar está ligado aos questionamentos. Entretanto, as perguntas devem ser encaradas e formuladas como elementos provocadores e mobilizadores que impulsionam os educandos a buscar elementos para suas análises e a construir conceitos e idéias. Sob esta perspectiva, avaliar consiste em formular questões e propor tarefas desafiadoras disponibilizando recursos necessários para que as crianças construam as respostas, segundo Hoffmann (2001).

Conforme a autora, este é o princípio da ação mediadora do professor no processo educativo: ele não acompanha apenas o aluno em sua ação-reflexão-ação, mas caminha lado a lado com o mesmo em sua trajetória. Este monitoramento por parte do professor favorece na tomada de consciência, por parte do aluno, quanto às possibilidades do processo de construção do conhecimento. Mas, para que isto ocorra é necessário ao professor ter clareza sobre cada momento vivenciado pelos educandos.

Com base no exposto, pode-se afirmar que a avaliação mediadora pode ser pensada como momentos de trocas de informações e idéias entre educadores e educados, nos quais, através do confronto de opiniões, objetiva-se possibilitar ao aluno alcançar sucessivamente estágios mais avançados, no que diz respeito à apreensão dos conhecimentos e conceitos elaborados. No entanto, por ser um processo interativo, não pode prescindir de uma maior aproximação entre professor e aluno, de forma a promover uma relação de confiança, na qual o aluno se sinta seguro para arriscar atitudes essenciais, durante sua trajetória.

Tendo em vista que a avaliação mediadora também tem como marca a ação reflexiva, é importante possibilitar aos educadores o exercício da reflexão, para que vivenciando seus benefícios possam incorporá-la a suas práticas cotidianas de sala de aula. Neste sentido, tanto é indispensável trabalhar a reflexividade docente para 
o desenvolvimento da sua consciência crítica e sua conscientização acerca de seu papel e responsabilidade para com a construção de uma educação de melhor qualidade que possa contribuir para a construção de tempos melhores para todos, indistintamente, quanto estabelecer uma nova razão professor-aluno, principalmente nas séries iniciais do Ensino Fundamental.

\section{Sobre a pesquisa desenvolvida...}

A pesquisa relatada foi desenvolvida em uma escola pública, vinculada ao Núcleo Regional de Ensino e localizada no campus da Universidade Estadual de LondrinaPR. 0 trabalho foi realizado junto às docentes das quatro primeiras séries do Ensino Fundamental que atuam no período matutino e vespertino, num total de oito professoras e às integrantes da equipe técnico-pedagógica da escola de ambos os períodos, que totalizavam cinco pessoas.

Iniciado em 2004, após a apresentação e aceitação da equipe da escola, foi realizado semanalmente um grupo de estudos durante todo ano letivo, que teve como tema a "avaliação formativa". Para tanto, foram elaborados mini-textos com base em Hoffman (2001). Outros temas abordados nesta etapa do trabalho foram: a importância da retomada do trabalho pedagógico, o acompanhamento da prática docente e a elaboração de um instrumento de acompanhamento do desempenho do aluno ao longo do ano letivo.

Paralelamente, realizou-se uma investigação acerca das práticas avaliativas realizadas pelas docentes. Isto se deu através da coleta de atividades dos alunos, de todas as séries, relacionadas aos conteúdos de cálculo, leitura e escrita, trabalhados ao longo dos bimestres.

A segunda fase, iniciada no ano de 2005 , teve como objetivo a elaboração de uma ficha para registro do desempenho dos alunos, bem como assessorar as docentes em seu preenchimento, visando avaliar as possibilidades de esta tornar-se um instrumento de acompanhamento do desenvolvimento do aluno e de apoio ao trabalho pedagógico. No entanto, o trabalho foi atravessado por uma solicitação do Núcleo Regional de Ensino-NRE, de que as escolas reorganizassem seu planejamento anual, passando a contemplar as dimensões: conceitual, histórica, social, cultural, psicológica e estética, conforme proposto por Gasparin (2005).

Em reunião, optou-se por focalizar no planejamento, além das dimensões propostas, as metas que as professoras pretendiam que fossem alcançadas por seus alunos ao trabalharem cada conteúdo especificado, bem como as estratégias metodológicas, os recursos a serem utilizados, os critérios e formas de avaliação correspondentes. Este trabalho foi realizado individualmente, junto a cada uma das professoras, nos horários em que as mesmas tinham hora-atividade, estendendo-se por todo primeiro semestre letivo de 2005. As integrantes da equipe da escola participaram de todo o processo. 
Concomitantemente a esta etapa, foi elaborada uma Ficha para Acompanhamento de Desempenho dos Alunos (FADA), posteriormente analisada e aprimorada junto às docentes. Na seqüência, iniciou-se a seleção e organização das atividades realizadas pelos alunos das diferentes séries em cada bimestre. Mediante a análise destas atividades, iniciou-se o preenchimento das fichas das respectivas turmas, objetivando efetuar o registro do maior nível de domínio alcançado por cada aluno, nos diferentes conteúdos trabalhados pelas docentes bimestralmente.

Após preenchimento das fichas referentes ao primeiro bimestre pelas pesquisadoras, as mesmas foram submetidas à análise das docentes e equipe, bem como foi iniciado o assessoramento individual das docentes para o preenchimento destas, mediante a realização de encontros semanais, visando auxiliá-las na avaliação e elaboração de estratégias de retomada dos conteúdos necessários junto aos alunos. Esta ação seguiu até o final de 2005, sendo que no término do período letivo da escola foi realizada uma reunião, na qual foi avaliado o trabalho desenvolvido e discutidas suas perspectivas de continuidade. Conforme previsão inicial esta atividade foi também desenvolvida nos anos posteriores.

Diferentemente do planejado, em 2006, as docentes não puderam assumir o preenchimento da ficha, pois praticamente todo quadro da escola foi modificado, ou seja, apenas uma docente permaneceu, em função da política vigente para contratação e alocação de docentes nas escolas no estado do Paraná, à época. Além disto, já no início deste ano, também mudaram a direção e a vice-direção da escola e, completando o quadro de mudanças, no início do segundo semestre letivo, foram substituídas a coordenadora geral e a supervisora do período matutino.

Diante deste fato, não poderiamos correr o risco de replicar todo procedimento e no futuro nos depararmos com a mesma situação. Assim, optamos por utilizar outra estratégia de trabalho. No primeiro bimestre, a ficha de acompanhamento foi preenchida pelas acadêmicas mediante observações realizadas nas salas de aula e a análise das atividades dos alunos coletadas junto às docentes. Tais atividades passaram a compor o portfólio destes, no intuito de que fosse continuado pelas docentes neste e nos anos subseqüentes, de modo a registrar o desempenho dos alunos ao longo de todo o ciclo de estudos.

Devido ao fato da ficha de acompanhamento ter sido preenchida pelas acadêmicas, neste primeiro momento, realizaram-se encontros semanais com as 'novas' docentes, individualmente, com a finalidade de expor-lhes os critérios de elaboração das referidas fichas e analisar as contribuições das informações aí contidas para a continuidade e direcionamento do trabalho docente. Nestas reuniões, também eram analisados os problemas do dia-a-dia de suas respectivas salas e trabalhada a auto-estima e autonomia das docentes para resolverem as situações no âmbito das mesmas. 
A partir do segundo bimestre deste ano, o preenchimento da FADA passou a ser solicitado às docentes, no intuito de favorecer sua apropriação do novo instrumento introduzido na escola. No entanto, foi mantido o auxílio semanal e individual às mesmas, destinando-os predominantemente à análise das estratégias de retomada dos conteúdos necessários junto aos alunos e à orientação quanto à postura a ser assumida nas situações de impasse.

De maneira complementar, realizava-se mensalmente uma reunião entre a equipe da escola e da pesquisa, para avaliação do trabalho e integração do conteúdo trabalhado pelas docentes junto às diferentes séries.

Ainda a partir do segundo bimestre iniciou-se o registro, mediante fotografia, das atividades desenvolvidas nas salas de aula, visando enriquecer o resgate da experiência e o portfólio dos alunos. Embora também estivesse planejada a filmagem das situações que permitissem avaliar o desempenho dos alunos no que se refere à sua integração e interação com a turma, envolvimento e participação nas atividades, pedagógicas e culturais, esta não pode ser realizada por não ter sido adquirida a filmadora solicitada pelo projeto em tempo hábil.

Durante todo desenvolvimento das etapas de trabalho relatadas, foram realizadas reuniões semanais da equipe de pesquisa para avaliação e planejamento das estratégias de trabalho. Além disto, a coordenadora do projeto responsabilizou-se pela condução do grupo de estudos e coordenação dos encontros mensais da equipe.

\section{Romper com a descontinuidade é possível?}

A etapa inicial do presente trabalho, que buscou investigar as práticas avaliativas vigentes no contexto da escola investigada, permitiu constatar o predomínio de avaliação formal e classificatória, característica da escola tradicional organizada em séries. Este fato demonstrava que a nova configuração do Ensino Fundamental, ou seja, a reorganização das séries em ciclos de estudos deu-se mais no plano legal, ou seja, não foi necessariamente acompanhada por um alinhamento das práticas avaliativas à nova configuração proposta.

Tendo em vista este fato, podemos observar, conforme afirma Perrenoud (1999), que apesar da proposição de mudança, corre-se o risco de que a avaliação continue a ser tomada apenas como um instrumento de classificação do aluno, mesmo que isto já não seja mais adequado a uma escola e sociedade que se pretendem firmar enquanto democráticas.

Diante deste cenário, a introdução do grupo de estudos tornou-se necessária e este atuou como um espaço para refletir a necessidade de superação das práticas classificatórias, e os fundamentos da avaliação processual, pois de acordo com Hoffman (2001), a superação 
do caráter classificatório deve ser realizada através de uma ação reflexiva-coletiva entre avaliadores e estudiosos. As reflexões realizadas neste espaço a respeito das práticas pedagógicas utilizadas analisavam em que medida estas permitiam às docentes observar o processo de aprendizagem dos alunos e não somente o ponto de chegada de cada um. Além disto, se alguma mudança precisava ser introduzida no cotidiano da escola, competiria aos educadores que integram seu quadro de pessoal realizá-las e não à equipe da pesquisa.

Esta foi uma das razões porque no início as docentes mostravam-se muito resistentes à proposta de implementação da avaliação formativa, apresentando principalmente questionamentos referentes à sobrecarga que esta prática poder-lhes-ia proporcionar. Além destes, também faziam menção a experiências que haviam tido em escolas anteriores e que as haviam marcado negativamente, pela desvalorização do conhecimento que possuiam.

Nesta ocasião, as docentes pouco diziam sobre suas vivências e dificuldades em sala de aula. No entanto, no decorrer dos encontros, seus questionamentos retratavam não mais resistência, mas o quanto desconheciam esta forma de avaliar e o interesse em conhecê-la começou a surgir. Com o passar do tempo, ao apreenderam que a avaliação continuada se dá no dia-a-dia da sala de aula, e que a proposta visava à concretização de uma ação conjunta e não uma simples imposição, suas atitudes passaram a ser de contribuição e de confiança quanto à possibilidade de fazer da avaliação formativa um instrumento efetivo em favor da aprendizagem dos alunos.

De acordo com Coelho (2003), a resistência por parte das docentes pode ser entendida como resultado de uma interferência na aceitação às inovações propostas, decorrente de fatores culturais. A autora destaca ser comum esta resistência inicial. Sua diminuição se dá na medida em que resultados positivos são observados ao longo do tempo. Pode-se dizer então, que a diminuição da resistência no decorrer dos grupos de estudos se deu pelo fato de, durante as discussões e reflexões realizadas, estas docentes observarem as contribuições que a prática da avaliação continuada poderia proporcionar à sua prática pedagógica.

Por outro lado, o grupo de estudos assegurava a existência um espaço de reflexão na instituição, o que foi também um resultado positivo obtido na presente pesquisa. Embora a existência de um espaço para estudos fosse garantida legalmente às instituições educacionais, este não era utilizado na ocasião por esta escola, e seu estabelecimento implicou em um remanejamento de atividades, havendo a necessidade de dispensar os alunos, quinzenalmente, o que foi negociado com os pais. Souza (2003) investigando este aspecto observou que este espaço não tem sido ocupado na grande maioria das escolas, por conta de não saberem o que fazer com a autonomia que lhes fora concedida. Neste sentido, o trabalho contribuiu para que este espaço de reflexão ganhasse sentido para a equipe docente e técnico-pedagógica desta escola. 
Considerando que a avaliação mediadora tem como marca a ação reflexiva, Hoffman (2001) afirma a importância de despertar nos educadores tal exercício. Este pensar reflexivo foi também um dos resultados obtidos pelo presente trabalho, na medida em que no decorrer dos encontros foi observada uma mudança de atitude das docentes, no sentido de romper com práticas das tradicionais escolas seriadas. Cabe destacar também o rompimento com o isolamento do trabalho docente, conforme observam Gorni e outros (2003), na medida em que as discussões acerca das questões do cotidiano e a troca de experiências passaram a fazer parte não só das reuniões como também do diaa-dia da escola. Além disto, no decorrer do trabalho houve muita colaboração das docentes no planejamento do trabalho das diferentes séries.

Embora fosse convocada individualmente a professora de cada série para a elaboração do planejamento, em todos os momentos docentes de outras séries, assim como a coordenadora, a orientadora e a supervisora da escola faziam questão de participar. Assim, foi durante esta etapa, em especial, que as docentes perceberam o quão importante era conhecer o planejamento de todas as séries, ou seja, a complementaridade do trabalho das diferentes séries. Isto ocorreu, pois, ao delimitarem-se os conteúdos, o nivel de complexidade e as estratégias com que cada série trabalharia, tornou-se inevitável definir os contornos do trabalho dos dois ciclos de estudos estabelecidos na escola. A partir de então, estabeleceu-se a 'cumplicidade' entre as docentes que passaram a consultar umas às outras para organizar seus próprios planejamentos.

Tendo em vista que é através dos questionamentos e troca de idéias entre professor e aluno que se dá a mediação, conforme Hoffman (2001), esta atitude das professoras foi uma forma de iniciarem tal exercício, para oportunizá-lo posteriormente aos alunos, em sala de aula.

0 auxilio ofertado para a organização do planejamento possibilitou ainda uma mudança de olhar na prática pedagógica por parte das docentes. Estas deixaram de estabelecer objetivos de ensino passando a explicitar os objetivos sob o ponto de vista da aprendizagem a ser alcançada pelos alunos. Isto significa que o planejamento que antes era direcionado para a ação do professor, passou a se orientar pela perspectiva da aprendizagem do aluno, buscando detectar quais ações dos discentes poderiam estar indicando seu nível de domínio acerca do conteúdo trabalhado.

Deve-se ressaltar que esta ampliação do foco do planejamento não foi uma ação de fácil compreensão e aceitação por parte das professoras. Havia dificuldade em descreverem o que esperavam dos alunos em cada conteúdo. Este fato fez que esta etapa se estendesse por um semestre.

As FADAs começaram a ser utilizadas no início de 2005. As atividades selecionadas para o preenchimento destas fichas eram extraídas do planejamento de cada 
bimestre, sendo relacionadas, inicialmente, às disciplinas de português e matemática. Bimestralmente, as docentes entregavam o planejamento das atividades de sua turma, para a elaboração da respectiva ficha. No entanto, algumas dificuldades surgiram no decorrer do trabalho impossibilitando o preenchimento total das mesmas. Dentre estas, destacam-se: algumas docentes forneciam as atividades realizadas pelos alunos aos poucos, um conteúdo de cada vez, havendo situações em que se recebia apenas uma atividade de cada aluno ou nenhuma.

Neste ano, apenas nos dois últimos bimestres as docentes passaram a fornecer mais atividades dos discentes, pois perceberam a contribuição que este quadro geral representava para a retomada do trabalho pedagógico. Na medida em que se verificava, mediante análise das fichas, a dificuldade de alguns alunos, ou da sala em geral, analisava-se as possiveis estratégias de continuidade e retomada de conteúdos junto aos mesmos. Aos poucos as docentes passaram a consultar as fichas por conta própria.

A avaliação positiva do trabalho no final deste ano gerou uma grande expectativa em todo grupo quanto à sua continuidade. No entanto, no primeiro dia do ano letivo de 2006, os alunos compareceram maciçamente às aulas, mas não havia nenhum professor para atendê-los, pois a equipe docente que atuaria na escola só se apresentou no segundo dia de aula, em função de ter ocorrido atraso na alocação dos docentes nas escolas pelo núcleo regional. Este fato impossibilitou o conhecimento a priori das 'novas' professoras, acerca do contexto em que trabalhariam. Assim, estas iniciaram imediatamente seu trabalho em sala de aula, o que inviabilizou até a realização do planejamento antecipadamente. Diante desta situação, a presença da equipe da pesquisa significou, de certa forma, uma grande fonte de apoio e auxílio no difícil momento que vivenciavam. Isto contribuiu para que, desde o início deste ano, fossem realizadas discussões sobre o dia-a-dia da escola e sobre o desenvolvimento das turmas.

Pode-se perceber que assim como cada aluno possui ritmo e formas de pensar diferenciadas, também o fazem os professores. Neste sentido é possivel afirmar que o trabalho realizado ocorreu sob configurações diferentes com cada uma das educadoras envolvidas. Porém, as diferenças existentes na forma de agir de cada uma foram se evidenciando com o passar do tempo.

Nas primeiras reuniões com as docentes, estas relatavam estar conhecendo a turma, seu ritmo de trabalho e o nivel de conhecimento dos alunos, ou seja, estavam fazendo o reconhecimento da realidade. Do nosso ponto de vista, tal fato significava que estávamos quase de volta ao ponto inicial, ou seja, contávamos apenas com uma professora que havia participado do trabalho realizado no ano anterior e, portanto, impedidas de dar continuidade ao mesmo. Novamente nos deparávamos com o desafio de realinhar as estratégias de trabalho. 
Infelizmente, ao final do ano seguinte, ou seja, de 2006 a situação se repetiu. Desta vez, quatro educadoras permaneceram na escola, sendo que apenas uma delas havia atuado como regente no ano anterior. A este respeito pudemos constatar, mais uma vez, a elevada rotatividade das docentes das séries iniciais do Ensino Fundamental. Este fato, além de extremamente prejudicial à qualidade da educação, e do trabalho pedagógico é também uma das contradições do próprio sistema na medida em que decorre das próprias políticas de contratação e alocação das docentes nas escolas.

Foi neste contexto, que no primeiro bimestre de 2006, quando as FADAs foram apresentadas às novas professoras da escola, estas se sentiram amparadas e foram receptivas à idéia de realização deste 'mapeamento' da sala. Relataram que através desta ficha poderiam ter uma visão geral da turma mais rapidamente, o que as auxiliaria no planejamento e continuidade do trabalho. Este fato se confirmou com o início do segundo bimestre, pois a consulta a estas fichas foi uma ação freqüente e as docentes decidiram utilizá-las para a elaboração do parecer parcial que deveriam fazer ao final do primeiro semestre. Tal opção foi justificada por elas, pelo fato das fichas permitirem a visualização das particularidades de cada aluno, já que continham tanto uma visão global da sala, como individual destes, evitando-se a construção de categorias padronizadas de desempenho, nas quais o único trabalho consiste em 'enquadrar' os alunos.

Diante deste bom manuseio das fichas por 50\% das docentes, a partir do segundo bimestre, as professoras foram solicitadas a preenchê-las. Estando em suas mãos, o preenchimento destas tornou-se mais completo e preciso, tendo em vista o maior conhecimento que as estas tinham de seus alunos.

Devido à responsabilidade assumida pelas docentes de preenchimento da FADA, esta passou a ser encarada, pelas mesmas, como uma fonte confiável de dados sobre o desempenho escolar dos alunos. Desta forma, no final do ano letivo de 2006, as professoras tomaram-na como base para a confecção do parecer final de cada aluno. Com isto superou-se a prática de pareceres descritivos separados por categorias, como ocorrera em anos anteriores e cada aluno teve seu parecer descrito de forma singular, caracterizando de fato seu processo de aprendizagem.

Por esta razão, pode-se considerar que tais pareceres podem consistir em documentos confiáveis para a escola, e contribuir para a continuidade do trabalho docente com a virada de ano letivo. Assim, as professoras que assumirem as turmas no ano letivo seguinte podem ter nestes pareceres instrumentos auxiliares para o planejamento de seu trabalho pedagógico e fontes adicionais de informações para o conhecimento da turma de alunos com irão trabalhar.

Cabe ressaltar que a atividade paralela de construção do portfólio de cada aluno foi realizada de maneira completa nos dois primeiros bimestres deste ano, tendo 
em vista que neles todas as docentes forneceram atividades suficientes para tal. No entanto, no segundo semestre letivo apenas uma docente continuou a fornecer tais atividades. As demais alegavam que na correria em cumprir com as exigências impostas pela escola, geralmente burocráticas, não tinham tempo para realizar outras atividades além das solicitadas nos cadernos e que pudessem ser utilizadas para a composição do portfólio dos alunos.

Este fato evidencia o quanto a organização do próprio sistema educacional, por vezes, impede a realização de um trabalho pedagógico de qualidade, comprometido com o desenvolvimento dos educandos que compõem o cenário educativo. Ao mesmo tempo sugere que, para as docentes parecia ser suficiente a realização da FADA enquanto instrumento de apoio ao trabalho pedagógico.

Nos encontros semanais dedicados à discussão do manuseio das fichas de acompanhamento, como instrumento de avaliação continuada do desempenho dos alunos, à retomada do trabalho docente diante das dificuldades tanto dos alunos, quanto das próprias docentes, assim como à adaptação de cada uma à escola e respectivas turmas, constatou-se a dificuldade das professoras em se adaptar ao novo ambiente, e por sua vez, o quanto as fichas podiam contribuir para seu conhecimento acerca dos discentes, na medida em que incentivavam a observação dos mesmos.

Por outro lado, o fato de as professoras terem constatado a validade da utilização das FADAs para direcionar sua ação pedagógica, reafirma o apontamento de Perrenoud (1999), de que, avaliação e ação pedagógica são tão relacionadas quanto interdependentes e não há como introduzir modificações em uma sem que se altere a outra.

Quanto à substituição das avaliações tradicionais pelas avaliações processuais, é possivel verificar que a primeira não foi abandonada, no entanto, a segunda passou a ocupar no decorrer do ano um lugar igualmente importante, tendo sido sua utilização, cada vez mais freqüente. Aos poucos, as docentes passaram a relatar situações de sala de aula que, para elas, representavam uma evidência da expressão do domínio do aluno acerca do conteúdo trabalhado, não se atendo mais, exclusivamente, às avaliações formais.

Isto está de acordo com o fato apontado por Hoffmann (2001), de que é no dia-a-dia da sala de aula que o aluno apresenta sinais indicando avanço em seu processo de aprendizagem. A avaliação mediadora organiza-se de tal forma a permitir que o professor consiga captar estes sinais que o aluno emite. É possivel que, com os encontros semanais, nos quais também se discutia a avaliação formativa, as docentes tenham passado a reconhecer os tipos de sinais do aluno e como utilizálos em prol da aprendizagem do mesmo. 
As reuniões mensais que ocorreram com todas as docentes envolvidas na pesquisa, favoreceram no sentido de apoiar e fortalecer no grupo o 'sujeito coletivo', bem como seus integrantes enquanto indivíduos comprometidos com um mesmo projeto, ou seja, como co-responsáveis pela aprendizagem escolar dos alunos ao longo do ciclo de estudos.

Acredita-se que estas reuniões atuaram no sentido de consolidar uma visão coerente do trabalho educativo e corroboram para a continuidade e aprimoramento do mesmo. Estes encontros, repletos de troca de idéias, dúvidas e experiências, oportunizaram o crescimento de todos os envolvidos.

A seu tempo, o bom relacionamento estabelecido com a equipe técnico-pedagógica e os demais funcionários da escola possibilitou que o entrosamento da equipe ocorresse de maneira natural, tranqüila e sem grandes dificuldades. Este fato pode ser tomado como mérito do trabalho, pois inserir-se na realidade é fundamental para o alcance do objetivo de introdução de mudanças no cotidiano escolar.

Por fim, cabe destacar que a presente pesquisa se deu em uma realidade dinâmica. Este fato nos obrigava a adequar constantemente nosso planejamento às possibilidades de trabalho de cada dia. Foi preciso aprender a lidar com esta condição de mudanças e imprevistos, característicos de contextos onde as coisas ocorrem em tempo real, não sendo possivel isolar ou manipular variáveis. Este fato pode ser encarado como um dos maiores desafios enfrentados pela equipe da pesquisa ${ }^{1}$, e que trata igualmente de conviver e sobreviver na realidade e no cotidiano investigado, numa relação de troca que se dá na medida em que compartilhamos o que sabemos e somos.

\section{Considerações finais}

Este trabalho permitiu a verificação da necessidade de superação das práticas pautadas na educação tradicional que ainda são realizadas no interior da escola. No entanto, a disposição para repensar e modificar tal prática só se transforma em ação concreta, quando envolve o próprio professor, que é um dos grandes protagonistas da educação.

Assim sendo, uma das formas de se garantir o início de um movimento de mudança no âmbito educacional, principalmente no que se refere às práticas avaliativas, condizentes com a nova estruturação do sistema educacional brasileiro está na criação de um espaço coletivo para estudos e reflexão nas escolas. Mediante tal espaço, os docentes se sentem 'autorizados' e 'encorajados' a exercerem sua profissão de maneira reflexiva, além de ouvidos em suas necessidades e enriquecidos pela troca de experiência com seus pares.

${ }^{1}$ Esta equipe era constituida por uma docente e quatro acadêmicas do $5^{\circ}$ ano do curso de Psicologia da UEL, duas das quais bolsistas de IC; uma pelo CNPq e outra pela ProPPG/UEL. 
A reflexão acerca da superação, de fato, do paradigma tradicional também implica em abrir campo para se pensar e trabalhar de maneira diferente a educação escolar. Neste sentido, o comprometimento do professor é o elemento que garante o trabalho em termos de qualidade e abertura a inovações e reflexões.

A pesquisa desenvolvida teve não apenas um caráter de investigação, mas também de intervenção, uma vez que seu objetivo era avaliar a possibilidade de implementação da avaliação formativa em uma escola pública da rede regular de ensino e, no entanto, não competia à equipe da pesquisa fazê-lo, mas aos próprios professores e equipe técnico-pedagógica da escola. Para tanto, obviamente teriamos que dar o suporte necessário, que neste caso consistiu na realização de um grupo de estudos sobre 0 tema, no auxílio ao planejamento escolar, na elaboração da FADA, no assessoramento para a utilização desta ficha em sala de aula, bem como na sua utilização para a retomada do trabalho docente junto aos alunos, quando necessário.

Sendo assim, para alcançar os objetivos propostos, mais que pesquisadores que buscam analisar dados de uma dada realidade, nos inserimos na vida da instituição, convivemos com os educadores por dois anos e, inevitavelmente passamos a fazer parte daquele contexto, e a nos sentir co-responsáveis pela qualidade da educação aí desenvolvida. Assim sendo, encerramos nosso projeto na escola, mas não nosso trabalho que se estendeu por 2007 e 2008.

A partir desta experiência, podemos afirmar, que o elemento mais desfavorável para o desenvolvimento de uma educação de qualidade na escola pública, com que nos deparamos foi a alta rotatividade dos docentes e dos educadores. Isto se deve ao fato de ela impedir não só a construção de um projeto de escola traçado no coletivo da escola, como também o comprometimento da equipe com a execução do projeto elaborado, e, por fim o estabelecimento de vínculos dos educadores com os alunos, com seus pares e com a comunidade em que a escola se insere.

Também consiste em um elemento que dificulta a melhoria da qualidade da educação, a ausência de um 'espaço coletivo' de trabalho, que permite a toda equipe da escola se envolver, dentro da sua jornada de trabalho, com a realização de estudos, reflexões, planejamento, troca de experiência e busca de soluções para as dificuldades presentes em seu cotidiano.

O estabelecimento deste espaço é condição indispensável para a consolidação da autonomia, já concedida às escolas. Sem este tempo para a realização do trabalho coletivo e sem a efetivação do corpo docente mediante a realização de concursos públicos, as escolas correm o risco de continuar organizadas em ciclos, mas trabalhando em séries; dos professores continuarem trabalhando isoladamente, sem tempo e condições de se comprometerem com a melhoria da qualidade da educação que desenvolvem, bem como com a aprendizagem dos alunos e com a qualidade dos cidadãos que ajudam a formar. 


\section{Referências}

COELHO, E. A. A progressão continuada no ensino fundamental e a cultura dos professores: uma contribuição para o entendimento dos elementos constitutivos de uma cultura enquanto facilitadores e inibidores de mudança. 2003. Tese (Doutorado) - Universidade Estadual Paulista, Marilia, SP, 2003.

DURAN, M. C. G.; ALVES, M. L.; PALMA FILHO, J. C. Vinte anos de política do ciclo básico na rede estadual paulista. Cadernos de Pesquisa, São Paulo, v. 35, n.124, p.83-112, jan./abr. 2005.

GASPARIN, J. L. Uma didática para a pedagogia histórico-crítica. Campinas, SP, Autores Associados, 2005.

GOMES, C. A. Desseriação escolar: alternativa para o sucesso? Ensaio: avaliação de políticas públicas em educação. Rio de Janeiro, v.13, n. 46, p.11-38, jan./mar. 2005.

GORNI, D. A. P. Reestruturação do ensino fundamental do Paraná após a abertura democrática do Brasil: retrospectiva e perspectivas. Londrina: Ed. UEL, 2002.

Sistema Estadual de Educação do Paraná: qualidade e avaliação. 1999. Tese (Doutorado) - Universidade Estadual Paulista. Marilia, SP, 1999.

GORNI, D.A. P. et al. A avaliação nas proposições do sistema e no contexto das escolas: um estudo em Londrina e microrregião. Londrina: Ed. UEL, 2003. . Relatório de Pesquisa.

HOFFMAN, J. Avaliar para promover: as setas do caminho. Porto Alegre: Ed. Mediação, 2001.

PERRENOUD, P. Avaliação: da excelência à regulação das aprendizagens: entre duas lógicas. Porto Alegre: Artes Médicas Sul, 1999.

SOUZA, M. R. Proposta pedagógica: instrumento de autonomia da escola?. 2003. Dissertação (Mestrado). Universidade Estadual de Londrina, Londrina, PR, 2003.

VALENTE, S. M. P. Parâmetros Curriculares Nacionais e avaliação na perspectiva do estado e da escola. 2002. Tese (Doutorado) - Universidade Estadual Paulista, Marília, SP, 2002.

Recebido em: 27/02/2008

Aceito para publicação em: 27/072009 